\title{
Erratum to: Urinary polyphenols and breast cancer risk: results from the Shanghai Women's Health Study
}

\author{
Jianfeng Luo $\cdot$ Yu-Tang Gao $\cdot$ Wong-Ho Chow $\cdot$ Xiao-Ou Shu \\ Honglan Li · Gong Yang • Qiuyin Cai · Nathaniel Rothman · Hui Cai • \\ Martha J. Shrubsole · Adrian A. Franke · Wei Zheng • Qi Dai
}

Published online: 25 October 2009

(C) Springer Science+Business Media, LLC. 2009

\section{Erratum to: Breast Cancer Res Treat \\ DOI 10.1007/s10549-009-0487-x}

In "Exposure measurement" section, sentence starting with "M4 from ... 121.0 (25 eV)." should read as "M4 from $\mathrm{m} / \mathrm{z} 223.2$ to $\mathrm{m} / \mathrm{z} 178.7(25 \mathrm{eV})$ and $\mathrm{m} / \mathrm{z} 137.8(25 \mathrm{eV})$; and for M6 from m/z 207.0 to $\mathrm{m} / \mathrm{z} 163.0(25 \mathrm{eV}), \mathrm{m} / \mathrm{z}$ $122.0(25 \mathrm{eV})$, and $\mathrm{m} / \mathrm{z} 121.0(25 \mathrm{eV}) . "$

The online version of the original article can be found under doi:10.1007/s10549-009-0487-x.

J. Luo $\cdot$ X.-O. Shu $\cdot$ G. Yang $\cdot$ Q. Cai $\cdot$ H. Cai ·

M. J. Shrubsole · W. Zheng · Q. Dai $(\bowtie)$

Department of Medicine, Vanderbilt Epidemiology Center, Institute for Medicine and Public Health, Vanderbilt-Ingram Cancer Center, Vanderbilt University School of Medicine, Sixth Floor, Suite 600, 2525 West End Avenue, Nashville, TN 37203-1738, USA

e-mail: qi.dai@vanderbilt.edu

W.-H. Chow · N. Rothman

Division of Cancer Epidemiology and Genetics, National Cancer Institute, NIH, Department of Health and Human Services, Bethesda, MD, USA

\section{Y.-T. Gao $\cdot$ H. Li}

Department of Epidemiology, Shanghai Cancer Institute, Shanghai, China

\section{A. A. Franke}

Cancer Research Center of Hawaii, University of Hawaii, 1236 Lauhala Street, Honolulu, HI 96813, USA

J. Luo

Department of Health Statistics and Social Medicine, School of Public Health, Fudan University, 200032 Shanghai, China 